\title{
FERRAMENTA DE MODELAGEM APLICADA A GERAÇÃO DE CAMADAS MATRICIAIS DE DECLIVIDADE
}

\author{
Giovanna Matos Antonio ${ }^{(a)}$,Alexandre Herculano de Souza Lima ${ }^{(b)}$ \\ (a) Departamento de Geografia/UFS, Universidade Federal de Sergipe, giovannamatos.antonio@ gmail.com \\ (b) Departamento de Geografia/UFS, Universidade Federal de Sergipe, dandefish@ hotmail.com

\section{Eixo: GEOTECNOLOGIAS E MODELAGEM ESPACIAL EM GEOGRAFIA FÍS IC A}

\section{Resumo}

O Model Builder (ArcGIS 10.3) é uma ferramenta de modelagem que permite a combinação de outras ferramentas pré-existentes no software para criar um modelo personalizado que agrupa procedimentos que devem ser tomadas para se chagar a um produto final em ambiente de Sistema de Informações Geográficas. As informações de declividade, por sua vez, exigem que seja executada uma série passos para que sejam obtidas com rigor técnico. Nesta perspectiva, o presente estudo objetivou criar um modelo personalizado para geração de camadas matriciais contendo informações de declividade de acordo com as normas contidas no Manual de Obtenção de Terras do INCRA (2006).

Palavras chave: Model Builder, ArcGIS 10.3, declividade, geoprocessamento.

\section{Introdução}

A partir do versão 9.2 do ArcGIS, software desenvolvido pela ESRI, é possível ter acesso à nova função denominada de Model Builder (ferramenta de modelagem), que trata-se de um criador de modelos personalizados, com a proposta de criar ferramentas a partir da integração de outras ferramentas já préexistentes no programa. Desta maneira, o Model Builder dispensa o conhecimento acerca de linguagem e programação para realizar estas tarefas, além otimizar o tempo de operação das atividades (LIMA, 2014).

O Manual de Obtenção de Terras e Perícia Judicial é um documento oficial que objetiva aprimorar os procedimentos técnicos, utilizados pelo INCRA nas atividades de vistorias, de fiscalização e de avaliação de terras, buscando pela pleno cumprimento da função social, assim como evidenciar o preço justo preço do imóvel rural (INCRA, 2006).

Dentre as informações técnicas abordados pelo Manual de Obtenção de Terras e Perícia Judicial consta um item denominado de descrição e classificação do relevo, o qual afirma que o relevo tem expressiva significância no que se refere às definições das classes de capacidade de uso das terras, pois ao apresentar uma relação indissociável com questões relacionadas ao uso e manejo agrícolas, torna-se imprescindível seu conhecimento. 
O tópico de descrição e classificação do relevo do manual em questão se atém a classificações relacionadas a graus de declividade, indicando ou restringindo usos específicos da terra para os determinados intervalos de classe.

Utilizando-se do Model Builder esta pesquisa objetivou criar um modelo personalizado que integre todas os procedimentos necessários para a criação de camadas do tipo raster contendo informações de declividade, tendo em vista a busca de diversos profissionais por este produto.

\section{Materiais e métodos}

Os procedimentos metológicos deste trabalho em suma se basearam na escolha das ferramentas necessárias para o processamento de modelos digitais de elevação (MDE) em ambiente de Sistemas de Informações Geográficas (SIG) para se chegar ao objetivo final. Para tanto, o primeiro passo necessário foi a aquisição de um MDE, o qual foi obtido através do sítio TOPODATA (Bando de dados Geomorfométricos) do INPE (Instituto Nacional de Pesquisas Espaciais) que disponibiliza gratuitamente este tipo de arquivo na resolução geométrica de $30 \mathrm{~m}$. Para este estudo foi escolhido a folha 10S375ZN situada em sua totalidade no estado de Sergipe.

O segundo passo foi a seleção e o texte das ferramentas preexistentes no Arctoolbox que deveriam compor o modelo final. A primeira ferramenta selecionada foi a copy raster encarregada por fazer uma cópia do MDE inserindo-o no processo de operação do modelo personalizado.

Para o cálculo da declividade fez-se necessário a reprojeção do MDE obtido, pois este procedimento é baseado em coordenadas projetadas. Os arquivos fornecidos pelo TOPODATA por padrão estão associados a projeções geográficas e ao datum WGS 84 , por este motivo foi selecionada a ferramenta project raster a qual ficou incumbida de reprojetar do MDE para o datam WGS 84 e para a projeção UTM zona 24S.

A terceira a última ferramenta a ser inserida no modelo foi a slope que realiza o cálculo de declividade tendo como produto uma camada matricial. Para a reclassificação das classes de declividade segundo os padrões do Manual de Obtenção de Terras e Perícia Judicial criou-se no ArcGIS 10.3 um arquivo XML contendo os intervalor de classe conforme o demonstrado na Figura 1. 


\begin{tabular}{|l|c|c|}
\hline $\begin{array}{c}\text { CLASSE DE } \\
\text { RELEVO }\end{array}$ & \multicolumn{2}{c|}{ CLASSES DE DECLIVIDADE } \\
\hline & $\%$ & Graus \\
\hline Plano & $0-2$ & $0^{\circ}$ a 1 ${ }^{\circ} 8^{\prime} 45^{\prime \prime}$ \\
\hline Suave Ondulado & $2-5$ & $1^{\circ} 8^{\prime} 45^{\prime \prime}$ a $2^{\circ} 51^{\prime} 45^{\prime \prime}$ \\
\hline $\begin{array}{l}\text { Moderadamente } \\
\text { Ondulado }\end{array}$ & $5-10$ & $2^{\circ} 5^{\prime} 1^{\prime} 45^{\prime \prime}$ a $5^{\circ} 42^{\prime} 38^{\prime \prime}$ \\
\hline Ondulado & $10-15$ & $5^{\circ} 42^{\prime} 38^{\prime \prime}$ a $8^{\circ} 31^{\prime} 51^{\prime \prime}$ \\
\hline Forte Ondulado & $15-45$ & $8^{\circ} 31^{\prime} 51^{\prime \prime}$ a $24^{\circ} 13^{\prime} 40^{\prime \prime}$ \\
\hline Montanhoso & $45-70$ & $24^{\circ} 13^{\prime} 40^{\prime \prime}$ a $34^{\circ} 59^{\prime} 31^{\prime \prime}$ \\
\hline Escarpado & $>70$ & $>34^{\circ} 59^{\prime} 31^{\prime \prime}$ \\
\hline \multicolumn{2}{|c|}{ TOTAL } \\
\hline
\end{tabular}

Figura 1 - Classes de declividade. (Fonte: INCRA, 2006).

\section{Resultados e discussão}

O modelo final foi denominado de Modelo para Geração de Declividade. Contou com a integração de três ferramentas no total, oriundas da toolset Raster Surface da toolbox 3D Analyst Tools e das toolset's Project Raster e Raster Dataset, ambas contidas na toolbox Data Management Tools. Este modelo contabilizou um tempo total de operação de 1 minuto e 2 segundos, mostrando-se como uma alternativa viável pois engloba todas procedimentos exigidos para o alcance do objetivo final em uma única janela.

O fluxograma utilizado na elaboração do modelo é apresentado a seguir:

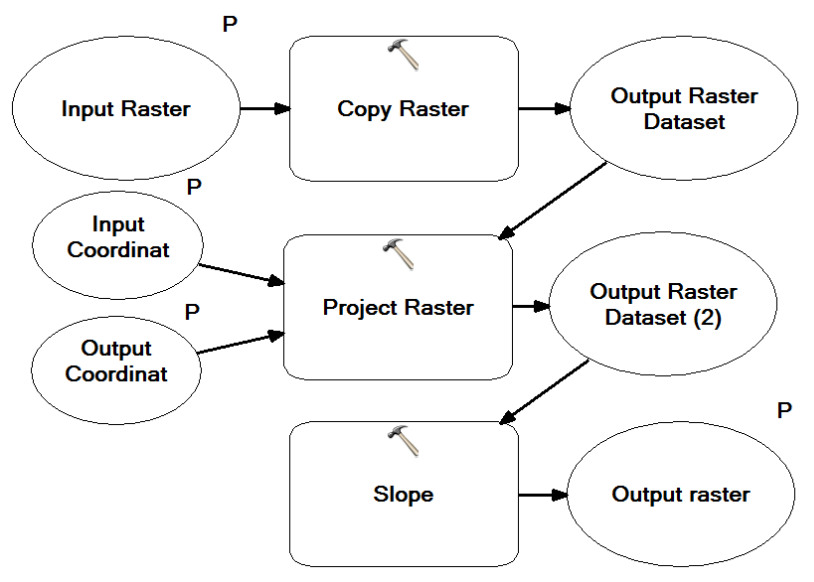

Figura 2 - Fluxograma do modelo para geração de declividade. 


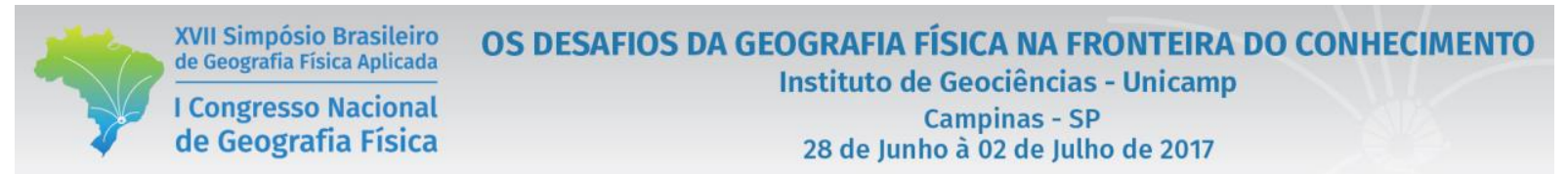

O camada matricial de declividade demonstrada parcialmente na Figura 3 foi gerada a partir do processamento da folha $10 \mathrm{~S} 375 \mathrm{ZN}$ sem impecílios, demonstrando estar preparada para a utilização em mapas de estudos que necessitem desta informação.

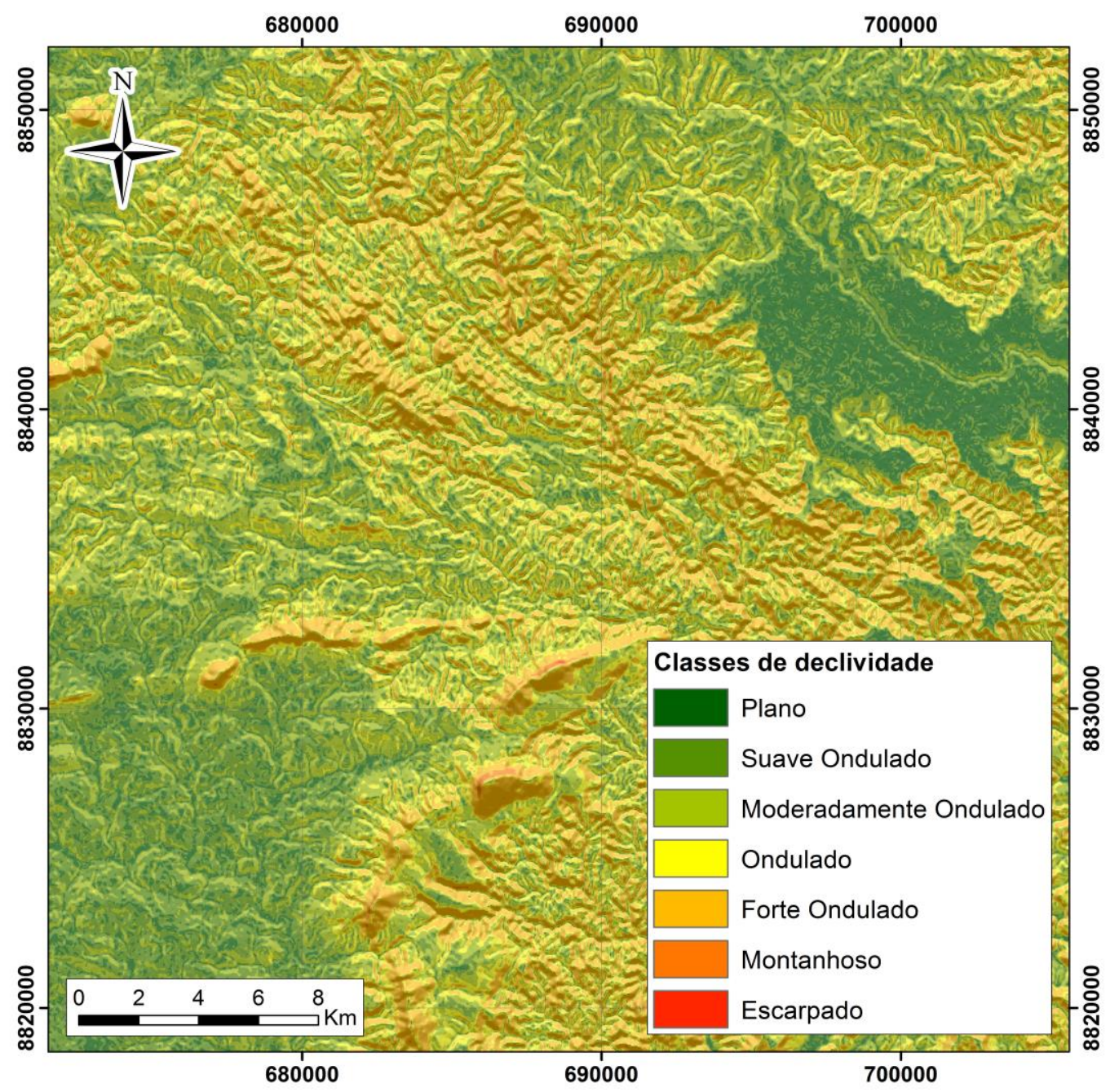

Figura 3 - Camada matricial de declividade.

\section{Conclusão}

O Model Builder demonstrou-se uma ferramenta eficaz para otimização de estudos desta natureza, propiciou um produto fidedigno, sendo assim considerado recomendável tanto para realização de trabalhos como este, como também para outros necessitem de procedimentos repetitivos e duradouros. 


\section{Bibliografia}

BARROSO, Renan Maron; MOURA, Edilberto Nunes de; GOMID, Carlos Antonio Sibut. O uso da ferramenta Model Builder para automatizar a delimitação de bacias hidrográficas em sistemas de informação geográfica, 2013. PUCPR. Curitiba - PR.

CEZARE, Cássio Henrique Giusti; FILHA, Lindomar Guedes Freire. Uso de ferramenta de modelagem (model Builder) para seleção de área com florestas ombrófila densa montana sobre solos do tipo latossolo amarelo e podzólico vermelho-amarelo no estado do Pará. Enciclopédia Biosfera, Centro Científico Conhecer, 2010. Goiânia - GO.

INCRA - Instituto Nacional de Reforma Agrária. 2006. Manual de obtenção de terras e perícia judicial. 140p.

LIMA, A. H. S; SOUZA, M. M. Uso do model builder (Arcgis 10.2) na elaboração de ferramenta de apoio a descrição de amostras litológicas macroscópicas no mapeamento geológico. Anais do XXI Encontro Estaudal de Geografia. Mossoró, 2014. p 542-550. 